\title{
Multi-attribute evaluation and deviation analysis of regional distribution network investment effect
}

\author{
Wu Jianbin ${ }^{1}$, Wang Zheng ${ }^{1}$, Gu Zhihong ${ }^{* 1}$, Liu Zhuo ${ }^{1}$ \\ ${ }^{1}$ State Grid Shanxi Economic Research Institute, 030002, China
}

\begin{abstract}
As the input ratio of regional distribution network increases year by year, higher requirements are put forward for high quality and high reliability of power consumption. Under this background, this paper involves 11 evaluation indexes from three dimensions of reliability, economy and environmental protection, and designs the evaluation index system of investment effect of regional distribution network. The multiattribute AHP-TOPSIS-entropy weight combination evaluation method for the investment effect of regional distribution networks is constructed. And select distribution network A, B, C area for example analysis, the results show that the $\mathrm{n}-1$ pass rate, power supply reliability, power consumption growth and emission reduction of clean energy generation are positively correlated with the investment effect of regional distribution network.
\end{abstract}

\section{Introduction}

As an important intermediate link of power supply and transmission, it is very important to analyze its investment. According to the current enterprise development goals and data characteristics of various indicators, the distribution network covers a number of equipment assets and has a large volume, but the data information is not complete, so that the investment effect is still not obvious ${ }^{[1]}$. At the same time, judging from the operation effect and investment efficiency of distribution network investment construction, the current investment effect also lacks comprehensive consideration and reasonable planning. Therefore, taking regional distribution network as the research object, it is of great significance to discuss and analyze the influencing factors of investment effect and track the weak links.

At present, many scholars have studied the investment effect of distribution network. Wu et al. [2] constructed a post-evaluation index system for the investment effect of distribution network from the two aspects of operation effect and investment efficiency generated by investment and construction. The evaluation method combining subjective and objective is adopted to put forward the calculation method of index weight and evaluation criterion in the post-evaluation system of distribution network investment effect. Wu et al. [3] based on the basic ledger of distribution network, constructed the evaluation index system of the basic ledger of distribution network, and analyzed the status quo of medium-voltage lines and low-voltage platforms in detail by using the scoring normalization method and weight optimization method. Li et al. [4] proposed an index system reflecting the investment benefit and decision-making level in view of the benefits generated by distribution network investment and construction projects, improved it by combining the advantages of grey correlation degree and TOPSIS method, and built an investment evaluation model based on improved grey correlation degree and TOPSIS. Liu et al. [5] combed out the existing investment benefit evaluation index of distribution network as the index source, used analytic hierarchy process to establish the pre-evaluation index system, and proposed the method to establish the final evaluation index system through the correlation analysis of distribution network investment projects. Sun et al. [6] took the investment effect of distribution network as the research object, established the system dynamics model and completed the evaluation of the investment effect of distribution network. Yang et al. [7] investigated the investment and construction effects of agricultural network projects of 27 provincial companies, established a comprehensive evaluation index system for the transformation and upgrading of agricultural network with 16 items in 3 categories, and conducted a comprehensive evaluation on the construction and transformation of agricultural network in typical counties with different development levels by using fuzzy evaluation method. However, as regional distribution network investment is an important stage, the above research only evaluates the effect under certain investment conditions, and does not reverse find the weak links of investment.

* Corresponding author: 381593857@qqa.com 
Based on this, by analyzing the investment status of regional distribution network, 11 evaluation indexes are involved from three dimensions of reliability, economy and environmental protection, and an evaluation index system of regional distribution network investment effect is designed and a hierarchical structure is constructed. By using the multi-attribute AHP-TOPSIS-entropy weight combination evaluation method, the investment effect of regional distribution network is calculated and the deviation is analyzed, and a series of improvement measures are put forward.

\section{Design the evaluation index system of regional distribution network investment effect}

In view of the operation effect generated by investment and construction of distribution networks, the evaluation index system of investment effect of regional distribution networks is mainly selected from three dimensions of reliability, economy and environmental protection. The specific effect index system is shown in Figure 1.

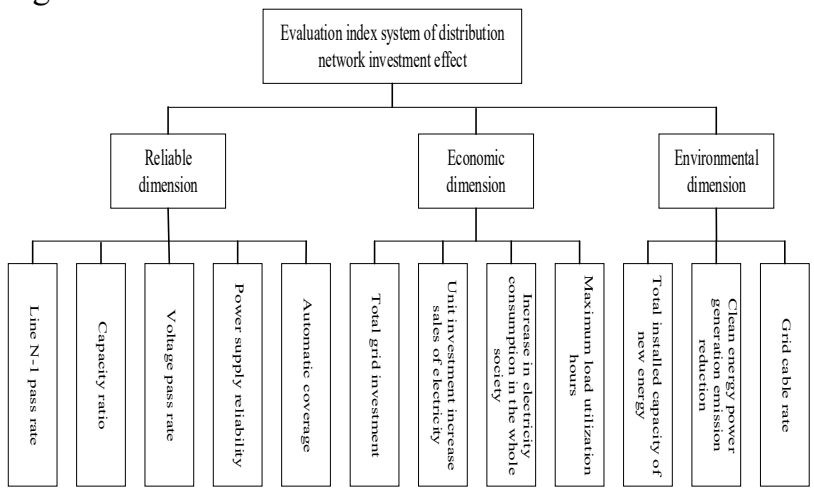

Fig 1 Evaluation index system of regional distribution network investment effect

\subsection{Reliability dimension}

The reliability dimension mainly involves five indicators, namely, n-1 pass rate, load capacity ratio, voltage qualification rate, power supply reliability and automation coverage rate [8]. Where, line N-1 pass rate is the concept of power supply reliability, which represents the degree of redundancy of a certain type of power supply equipment in a specific scope of the power network. If there are two transmission lines between two substations, the reliability of the line is $\mathrm{N}-1$, because when one line is out of service due to fault or maintenance, the two substations can still maintain effective electrical contact, ensuring the power supply of important users. Capacity-load ratio is the ratio between the total capacity of substation equipment in a power supply area and the maximum load in the power supply area, that is:

$$
R_{s}=K_{1} \times K_{4} / K_{2} \times K_{3}
$$

Where, $R_{s}$ represents the capacity-load ratio; $K_{1}$ denotes the load dispersing system; $K_{2}$ represents the safe operation rate of transformer; $K_{3}$ represents the transformer operation rate; $K_{4}$ denotes the reserve coefficient.

Voltage qualification rate refers to the percentage of the total time that the voltage at the monitoring point is within the qualified range and the total time of monthly voltage monitoring within one month during the operation of the power grid. Power supply reliability refers to the continuous power supply ability of the power supply system, which is an important index to assess the power quality of the power supply system. It reflects the degree of power industry's satisfaction of the national economic power demand, and has become one of the standards to measure the economic development degree of a country.

\subsection{Economic dimension}

The economic dimension involves four indicators, namely, total investment in power grid, increase of electricity sold per unit investment, increase of electricity consumption of the whole society and maximum hours of load utilization. Among them, the total investment in power grid increases year by year with the continuous expansion and increase of power grid enterprise construction. It is a positive indicator to measure how much income each unit investment cost can bring. The electricity consumption of the whole society is used for economic statistics. It refers to the total consumption of electric energy in all areas such as the primary, secondary and tertiary industries in a region, mainly including industrial, agricultural, commercial, residential, public facilities and other electricity consumption. The annual maximum load utilization hour refers to the ratio of the annual electricity consumption of the user or region to the maximum load that occurs in the current year of the user or region. Under normal circumstances, the annual maximum load utilization hour is the annual actual electricity consumption, according to the equivalent electricity hours converted by the maximum load, its value should be less than or equal to $8760 \mathrm{~h}$, commonly used to predict the maximum load.

\subsection{Environmental dimension}

The dimension of environmental protection involves three indicators, namely, the total installed capacity of new energy, the emission reduction of clean energy power generation and the rate of power grid cable. Among them, with China's vigorous development of wind power, photovoltaic and other renewable energy, its installed capacity increases year by year, but access to the power system disturbs the stability of its own system, bringing a certain impact. Clean energy power generation emission reduction considering the new energy grid, directly reduce the emission of carbon 
dioxide, sulfur dioxide and other pollutants. Power cables are cables used to transmit and distribute electrical energy. They are often used in urban underground power grids and power station outlet lines. Their proportion has increased year by year, including power cables with various voltage levels and insulations of $1-500 \mathrm{KV}$ and above.

\section{Construct multi-attribute portfolio model of regional distribution network investment effect}

Based on the idea of combination method, this paper proposes multi-attribute AHP-TOPSIS-entropy grouping method for investment effect of regional distribution networks [9]. This method uses AHP method to determine the subjective weight of the investment effect evaluation index, and entropy weight method to determine the objective weight of the investment effect evaluation index. The specific model ideas are as follows:

\subsection{The idea of investment effect multi-attribute portfolio model}

Based on the principle of multi-attribute AHP-TOPSISentropy weight grouping of regional distribution network investment effect, the hierarchical structure of target layer, criterion layer and index layer is considered. The specific ideas are as follows:

(1) Establish a hierarchical structure index system for the investment effect of regional distribution networks, that is, the target is the investment effect of regional distribution networks, and the criterion layer is the reliability dimension, economic dimension and environmental dimension. The index layers are the N-1 pass rate, capacity ratio, voltage qualification rate, power supply reliability, automation coverage rate, total investment in the power grid, increase of electricity sold per unit investment, increase of electricity consumption in the whole society, maximum load utilization hours, total installed capacity of new energy, emission reduction of clean energy power generation and power grid cable rate.

(2) AHP is selected as the subjective weight determination method, entropy weight method is selected as the objective weight determination method, and the subjective weight of all the obtained effect indexes is modified to finally obtain the weight value of the combination of subjective and objective of each effect index.

(3) Multi-attribute AHP-TOPSIS-entropy weight grouping method is adopted to evaluate the investment effect indexes of regional distribution networks.

(4) Analyze the investment effect evaluation results of regional distribution network.

\subsection{Construct the multi-attribute portfolio model of investment effect}

Each effect index of regional distribution network was assigned to form an initial matrix $M$, and the evaluation was carried out by means of multi-attribute AHP-TOPSIS-entropy weight grouping method. The specific model was constructed as follows:

(1) According to the investment effect index information of regional distribution network, value is assigned. The initial matrix is denoted as $M$, namely:

$$
M_{i j}=\left[\begin{array}{cccc}
M_{11} & M_{21} & \cdots & M_{m 1} \\
M_{12} & M_{22} & \cdots & M_{m 2} \\
\vdots & \vdots & \cdots & \vdots \\
M_{1 n} & M_{2 n} & \cdots & M_{m n}
\end{array}\right]
$$

(2) Standardize the index data to obtain a standardized decision matrix, namely:

$$
P_{i j}=\left[\begin{array}{cccc}
P_{11} & P_{21} & \cdots & P_{m 1} \\
P_{12} & P_{22} & \cdots & P_{m 2} \\
\vdots & \vdots & \cdots & \vdots \\
P_{1 n} & P_{2 n} & \cdots & P_{m n}
\end{array}\right]
$$

(3) AHP-entropy weight method is used to determine the weight of investment effect indexes, namely: ${ }^{w_{j}}$.

(4) Determine the weighted evaluation value matrix of investment effect indexes, namely:

$$
V=\left(w_{j} P_{i j}\right)_{m n}=\left[\begin{array}{cccc}
w_{1} P_{11} & w_{1} P_{21} & \cdots & w_{1} P_{m 1} \\
w_{2} P_{12} & w_{2} P_{22} & \cdots & w_{2} P_{m 2} \\
\cdots & \cdots & \cdots & \cdots \\
w_{m} P_{1 n} & w_{m} P_{2 n} & \cdots & w_{m} P_{m n}
\end{array}\right]
$$

(5) Positive ideal scheme and negative ideal scheme are determined by TOPSIS method, namely:

$$
\begin{aligned}
& V^{+}=\left\{v_{1}^{+}, v_{2}^{+}, K, v_{n}^{+}\right\}=\left\{\left(\max _{i} v_{i j} \mid j \in J_{1}\right),\left(\min _{t} v_{i j} \mid j \in J_{2}\right) \mid i=1,2, K, m\right\} \\
& V^{-}=\left\{v_{1}^{-}, v_{2}^{-}, K, v_{n}^{-}\right\}=\left\{\left(\min _{i} v_{i j} \mid j \in J_{1}\right),\left(\max _{t} v_{i j} \mid j \in J_{2}\right) \mid i=1,2, K, m\right\}
\end{aligned}
$$

(6) Calculate the Euclidean distance of the scheme,

$$
S_{1}^{+}=\sqrt{\sum_{j=1}^{n}\left(v_{i j}-v_{j}^{+}\right)^{2}}, S_{1}^{-}=\sqrt{\sum_{j=1}^{n}\left(v_{i j}-v_{j}^{-}\right)^{2}}
$$

The degree of closeness, that is

$$
e_{i}=\frac{S_{i}^{-}}{S_{i}^{+}+S_{i}^{-}}
$$

\subsection{Calculation steps of investment effect multi- attribute portfolio model}

According to the ideas and construction principles of the regional distribution network investment effect portfolio model given in the previous section, the specific calculation steps are shown in Figure 2. 


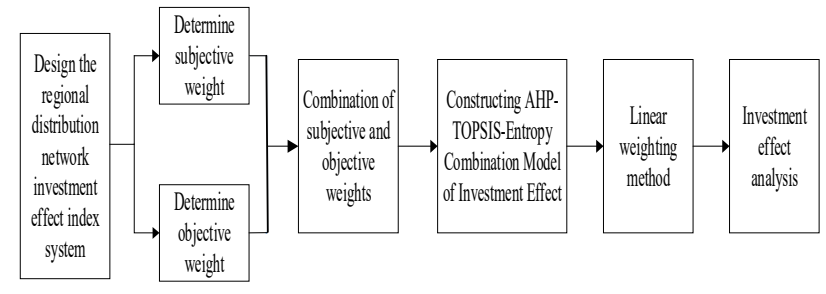

Fig2. Specific calculation diagram of investment effect portfolio model

\section{Case Analysis}

In order to verify the validity of the proposed model, three typical regions were selected for the recent three years of research and statistical data analysis.

\subsection{Calculate the index weight of investment effect}

According to the AHP-TOPSIS-entropy weight grouping method of regional distribution network investment effect proposed in this paper, the weight of each effect index is calculated, as shown in Table 1.

Table 1 Comprehensive weight of each index

\begin{tabular}{cccc}
\hline $\begin{array}{c}\text { Performance } \\
\text { index }\end{array}$ & $\begin{array}{c}\text { Objective } \\
\text { weight }\end{array}$ & $\begin{array}{c}\text { Subjective } \\
\text { weight }\end{array}$ & $\begin{array}{c}\text { Comprehensive } \\
\text { weight }\end{array}$ \\
\hline $\begin{array}{c}\text { Line N-1 pass } \\
\text { rate }\end{array}$ & 0.163 & 0.178 & 0.171 \\
\hline Capacity ratio & 0.059 & 0.134 & 0.097 \\
\hline $\begin{array}{c}\text { Voltage pass } \\
\text { rate }\end{array}$ & 0.033 & 0.152 & 0.093 \\
\hline $\begin{array}{c}\text { Power supply } \\
\text { reliability }\end{array}$ & 0.109 & 0.055 & 0.082 \\
\hline $\begin{array}{c}\text { Automatic } \\
\text { coverage }\end{array}$ & 0.032 & 0.069 & 0.051 \\
\hline $\begin{array}{c}\text { Total grid } \\
\text { investment }\end{array}$ & 0.072 & 0.044 & 0.058 \\
\hline $\begin{array}{c}\text { Unit } \\
\text { investment } \\
\text { increase sales } \\
\text { of electricity }\end{array}$ & 0.087 & 0.071 & 0.079 \\
\hline $\begin{array}{c}\text { Increase in } \\
\text { electricity } \\
\text { consumption } \\
\text { in the whole } \\
\text { society }\end{array}$ & 0.156 & 0.045 & 0.101 \\
\hline $\begin{array}{c}\text { Maximum } \\
\text { load } \\
\text { utilization } \\
\text { hours }\end{array}$ & 0.038 & 0.060 & 0.049 \\
\hline $\begin{array}{c}\text { Total installed } \\
\text { capacity of } \\
\text { new energy }\end{array}$ & 0.061 & 0.070 & 0.066 \\
\hline $\begin{array}{c}\text { Clean energy } \\
\text { power } \\
\text { generation } \\
\text { emission } \\
\text { reduction }\end{array}$ & 0.106 & 0.065 & \\
\hline $\begin{array}{c}\text { Grid cable } \\
\text { rate }\end{array}$ & 0.084 & 0.057 & \\
\hline & & & \\
\hline
\end{tabular}

\subsection{Calculate the comprehensive evaluation value of each region}

On the basis of the comprehensive weight of each investment effect index calculated in Table 2, standardized processing and ROPSIS method were used to calculate the comprehensive evaluation value. The results are shown in Table 2.

Table 2 Evaluation values of different regions

\begin{tabular}{cccccc}
\hline & Region & $\begin{array}{c}\text { Reliab } \\
\text { le } \\
\text { dimen } \\
\text { sion }\end{array}$ & $\begin{array}{c}\text { Economi } \\
\text { c } \\
\text { dimensi } \\
\text { on }\end{array}$ & $\begin{array}{c}\text { Environme } \\
\text { ntal } \\
\text { dimension }\end{array}$ & Value \\
\hline \multirow{2}{*}{201} & Area A & 0.492 & 0.287 & 0.222 & 0.349 \\
\cline { 2 - 6 } 6 & Area B & 0.507 & 0.261 & 0.232 & 0.351 \\
\cline { 2 - 6 } & Area C & 0.326 & 0.383 & 0.291 & 0.333 \\
\hline \multirow{2}{*}{201} & Area A & 0.512 & 0.273 & 0.215 & 0.351 \\
\cline { 2 - 6 } 7 & Area B & 0.344 & 0.277 & 0.379 & 0.334 \\
\cline { 2 - 6 } & Area C & 0.446 & 0.347 & 0.207 & 0.345 \\
\hline \multirow{2}{*}{201} & Area A & 0.483 & 0.196 & 0.321 & 0.348 \\
\cline { 2 - 6 } 8 & Area B & 0.396 & 0.423 & 0.181 & 0.340 \\
\cline { 2 - 6 } & Area C & 0.466 & 0.346 & 0.188 & 0.347 \\
\hline \multirow{2}{*}{$\mathrm{It}$} & can be sen from & &
\end{tabular}

It can be seen from the above evaluation value that the development trend of region $\mathrm{B}$ and region $\mathrm{C}$ is roughly the same, from low to high, while the development trend of region A is relatively stable in the past three years without great changes, and it belongs to the region with good investment effect among the three regions. Therefore, after obtaining the data of the last three years, we can further analyze the deviation of influencing investment effect in Regions A, B and C.

\subsection{Analyze the investment effect deviation of each region}

Based on the comprehensive weight and evaluation value of different regions $\mathrm{A}, \mathrm{B}$ and $\mathrm{C}$ calculated in the previous section, the deviation is further analyzed, as shown in Figure 3.

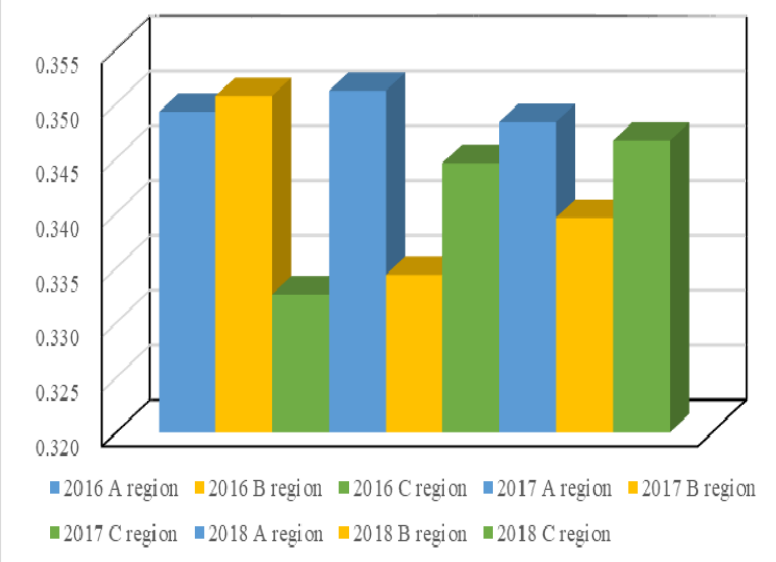

Fig3 Deviation analysis in A, B and C

It can be seen from Figure 3 that the investment performance of Region A was in the best state in 2017, and then declined by $3 \%$ in 2018 . The trend of Region B has the best investment effect in 2016, but it can be seen from the data of 2017 and 2018 that the investment effect is relatively unstable. From 2016 to 2018, the investment effect of Region $\mathrm{C}$ tends to be in a good state. 
At the same time, the investment effect deviation analysis of the three regions shows that the investment effect of the A region is significantly better than that of the $\mathrm{B}$ and $\mathrm{C}$ regions, but the investment effect of the $\mathrm{A}$ region and the $\mathrm{B}$ region is the same, and it has not developed to a favorable trend.

According to the reliable dimension data of 2016, 2017 and 2018, it can be seen that the pass rate of line N1 and the reliability of power supply have A great influence on the reliability dimension, so the reliability of power supply in regional distribution network should be strengthened. In 2017, region A has the highest weight of reliable dimension index, but it still has some volatility. The growth of electricity consumption in the whole society has the greatest impact on the investment effect in the economic dimension. Region $\mathrm{B}$ and $\mathrm{C}$ reached a certain height in 2016 and 2018 respectively. Clean energy power generation takes up a large share in the environmental dimension, which clearly shows that with the increase and expansion of new energy installed capacity, regions $\mathrm{A}, \mathrm{B}$ and $\mathrm{C}$ have relatively prominent effects on energy conservation and emission reduction, and regional investment has brought positive effects.

\section{Conclusion}

In view of the lack of comprehensive consideration of the investment effect of existing regional distribution networks and the insufficient quantification of investment effect evaluation, this paper proposes a multiattribute AHP-TOPSIS-entropy weight method, and the specific research results are as follows:

(1) From three dimensions of reliability, economy and environmental protection, this paper considers 11 investment effect indexes and designs the evaluation index system of regional distribution network investment effect.

(2) Based on the drawbacks of the pure subjective weight method, the combined evaluation method of multi-attribute AHP-TOPSIS-entropy weight is proposed, which can evaluate the investment effect of regional distribution network in a more practical way.

(3) Three regions A, B and C were selected for example analysis, and the effect indexes such as the pass rate of line $\mathrm{N}-1$, the reliability of power supply, the growth rate of electricity consumption of the whole society, and the emission reduction of clean energy generation were pointed out, which affected the investment effect of regional distribution network to different degrees, and the improvement and management of investment effect needed to be strengthened.

\section{Acknowledgement}

Project Supported by Research on device asset performance evaluation model and configuration optimization technology of Shanxi distribution network under Energy Internet (SGTYHT/18-JS-206).

\section{Reference}

1. Engineering; Hunan University Details Findings in Engineering (Robust Semisupervised Generative Adversarial Networks for Speech Emotion Recognition Via Distribution Smoothness)[J]. Journal of Engineering,2020.

2. WU Zheng, CUI Wenting, et al. Post-evaluation and Rationality Analysis of Distribution Network Investment[J]. Proceedings of the CSU-EPSA, 2016, 28(12): 96-102.

3. WU Xia, ZHANG Yi, et al. Investment Decision Analysis of Distribution Network Project Under $10 \mathrm{kV}$ and Below Based on Basic Account[J]. Techniques of Automation and Applications, 2019,38(10):103-106.

4. LI Xiaojun, LIANG Jifeng, et al. Investment Assessment on Distribution Network Projects Based on Improved Grey Correlation Degree and TOPSIS method[J]. Northeast Electric Power Technology, 2017, 38(08):56-59.

5. LIU Fuyan. Study on Investment Efficiency Evaluation System for Distribution Networks Based on Investment Correlation Analysis [J]. Zhejiang Electric Power, 2016, 35(03):68-71.

6. SUN Junting. Evaluation of Investment Effect of Distribution Network Based on System Dynamics[D]. Beijing Jiaotong University, 2016.

7. YANG Honglei, SHENG Wanxin, et al. Analysis on the Investment Effect of Rural Power Network Reconstruction and Upgrading Project Based on Fuzzy Evaluation Method [J]. Advanced Technology of Electrical Engineering and Energy, 2015, 34(02):55-60.

8. Yanxin Chai,Yue Xiang, et al. Investment decision optimization for distribution network planning with correlation constraint[J]. International Transactions on Electrical Energy Systems, 2020, 30(7).

9. Jie Yu,Fengting Li,et al. Spatiotemporal evolution of tropical forest degradation and its impact on ecological sensitivity: A case study in Jinghong, Xishuangbanna, China[J]. Science of the Total Environment, 2020, 727. 